\title{
Distributed Voltage Control with Electric Springs: Comparison with STATCOM
}

\author{
X. Luo, Student Member, IEEE, Z. Akhtar, Student Member, IEEE, C.K. Lee, Member, IEEE, \\ B. Chaudhuri, Senior Member, IEEE, S.C. Tan, Senior Member, IEEE, and S.Y.R. Hui, Fellow, IEEE
}

\begin{abstract}
The concept of 'Electric Spring (ES)' has been proposed recently as an effective means of distributed voltage control. The idea is to regulate the voltage across the 'critical loads' while allowing the 'non-critical' impedance-type loads (e.g. water heaters) to vary their power consumption and thus contribute to demand-side response. In this paper a comparison is made between distributed voltage control using ES against the traditional single point control with STATCOM. For a given range of supply voltage variation, the total reactive capacity required for each option to produce the desired voltage regulation at the point of connection is compared. A simple case study with a single ES and STATCOM is presented first to show that the ES and STATCOM require comparable reactive power to achieve similar voltage regulation. Comparison between a STATCOM and ES is further substantiated through similar case studies on the IEEE 13-bus test feeder system and also on a part of the distribution network in Sha Lo Wan Bay, Hong Kong. In both cases, it turns out that a group of ESs achieves better total voltage regulation than STATCOM with less overall reactive power capacity. Dependence of the ES capability on proportion of critical and non-critical load is also shown.
\end{abstract}

Index Terms - Demand response, Electric springs, STATCOM, Voltage control, Voltage regulation.

\section{I.INTRODUCTION}

$\mathrm{V}$ OLTAGE control in medium voltage (MV) or low voltage (LV) distribution networks is typically exercised through transformer tap-changers and/or switched capacitors/reactors. Sometimes a STATic COMpensator (STATCOM) is used for fast and precise voltage regulation, especially for the sensitive/critical loads [1].

The novel concept of 'Electric Spring (ES)' has been proposed as an effective means of distributed voltage control [2]. The idea is to regulate the voltage across the 'critical

This work was supported in part by the Commonwealth fellowship, the Hong Kong Research Grant Council under Grant HKU10/CRG/10 and the University of Hong Kong Seed Funds (Seed Projects: 201111159239 \& 201203159010).

X. Luo, C.K. Lee and S.C. Tan are with the Department of Electrical \& Electronic Engineering, The University of Hong Kong (e-mail: luoxiao@eee.hku.hk; cklee@eee.hku.hk; sctan@eee.hku.hk). Z. Akhtar and B. Chaudhuri are with the Department of Electrical \& Electronic Engineering, Imperial College London (e-mail: z.akhtar13@imperial.ac.uk; b.chaudhuri@imperial.ac.uk).

S.Y.R. Hui is with the Department of Electrical \& Electronic Engineering, The University of Hong Kong (e-mail: ronhui@eee.hku.hk) and also with Imperial College London (e-mail: r.hui@imperial.ac.uk). loads' while allowing the 'non-critical' impedance-type loads (e.g. water heaters) to vary their power consumption and thus contribute to demand-side response $[3,4]$ as well. This would allow and facilitate large penetration of intermittent renewable energy sources without requiring huge amounts of energy storage to act as a buffer between supply and demand [5]. The basic proof of concept of ES has already been demonstrated through hardware experimentation with the developed prototypes [2, 6]. Distributed voltage regulation through collective action of a cluster of ESs, each employing droop control has also been illustrated [7].

In this paper the focus is to compare the effectiveness of single point voltage control using STATCOM against distributed voltage control using a group of ESs. The basis for comparison is total voltage regulation (root mean square of the deviation of the actual voltages from the rated (1.0 p.u) values) achieved and the overall reactive capability required for each option in order to achieve that $[8,9]$.

A number of papers $[2,5-7]$ have been published recently on the Electric Spring concept and its control. However, none of those papers have focused on the collective performance of multiple of ESs considering realistic distribution networks. This paper demonstrates the effectiveness of multiple ESs working in unison through case studies on an IEEE test feeder network and also a part of a real distribution system in Hong Kong. The voltage regulation performance and total reactive power requirement of a group of ESs in case of distributed voltage control is compared against the single-point control using a STATCOM. In both cases, it turns out that a group of ESs achieves better total voltage regulation than STATCOM with less overall reactive power capacity.

\section{II.ELECTRIC SPRING CONCEPT}

Voltage control in LV and MV distribution networks and demand-side management (DSM) have traditionally been treated and tackled separately. Voltage control is usually achieved by control devices discussed in the previous section. Demand-side management on the other hand is employed in a more distributed fashion (often at the appliance level) and is predicated on intelligence or communication facility in the appliance [10-12].

Alternatively, an integrated approach to voltage control and aggregated demand action could be achieved by separating the loads into critical loads requiring constant voltage and uninterrupted supply and non-critical, impedance-type loads. At times of generation shortfall or network constraint, the voltage of the non-critical loads is reduced while regulating the voltages across the critical loads. This addresses the 
generation shortfall or network constraint and also facilitates better voltage regulation of the critical loads through manipulation of the supply impedance voltage drop.

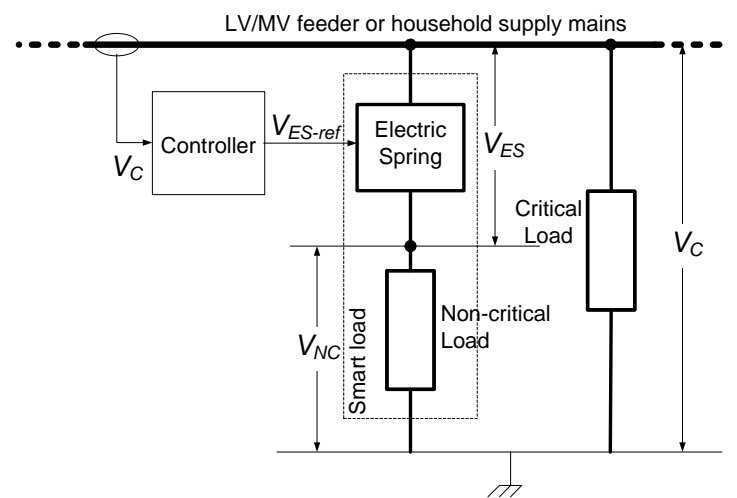

Fig. 1. Electric Spring set-up for Smart loads.

One way to exercise this control is to use the so called Electric Springs (ESs) which are power electronic compensators that inject a voltage with controllable magnitude $V_{E S}$ in series with each non-critical load to regulate the voltage $V_{C}$ across the critical load as shown in Fig. 1 . The voltage $V_{N C}$ across the non-critical loads is thus controlled (within allowable bounds) and the active power consumed by them modulated. The series combination of the ES and the noncritical load thus acts as a 'Smart Load' which ensures tightly regulated voltage across the critical load while allowing its own power consumption to vary and thereby, participate in demand side response. Adding the voltage $V_{E S}$ in quadrature with the current flowing through the ES ensures exchange of reactive power only like conventional voltage compensators including STATCOM. For further details about Electric Springs the readers can refer to $[2,5]$.

\section{III.ELECTRIC SPRING (ES) VS. STATCOM}

\section{A.Test System}

In order to compare the voltage regulation performance of a single ES against that of a STATCOM, a simple test system as shown in Fig. 2 was considered.

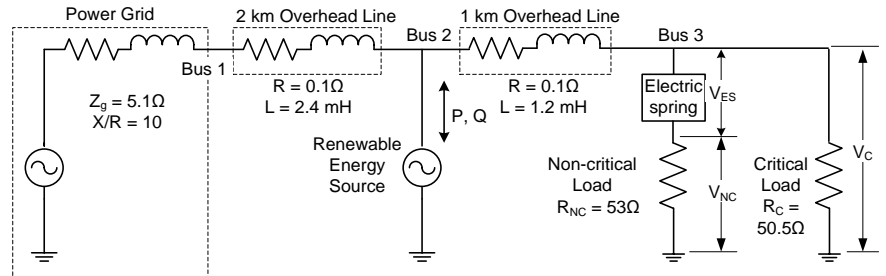

Fig. 2. Simulation set up with an intermittent source and an equivalent power grid.

It comprises of a power source acting as the main power grid and a separate controllable power source to emulate an intermittent renewable energy source. The controllable source is capable of injecting variable active and/or reactive power which causes the voltage across the critical load to fluctuate. For simplicity both critical and non-critical loads were represented by resistors although they do not have to be necessarily resistive. The parameters used for the system and the ES are the same as in [2] and are not repeated here due to space restriction.

The above system was modeled in Matlab/SIMULINK using a controllable voltage source representation for both ES and STATCOM. Modeling and control of ES is discussed in [13]. The magnitude of the controllable voltage representing the ES is controlled using a PI controller to minimize the difference between the actual and reference values of the voltage across the critical load. Phase angle of the voltage source is locked in quadrature to the phase angle of series current to ensure there is no active power transfer. The STATCOM is modeled by a controllable voltage source in series with impedance. Its control circuit is very similar to that of ES except for the adjustments due to its parallel connection to the critical and non-critical load.

\section{B. Voltage Suppress Mode}

The voltage across the loads was increased above the nominal value $(216 \mathrm{~V})$ by reducing the reactive power absorption of the renewable source. This is to test the ability of an ES and a STATCOM to suppress the voltage and regulate it at the nominal value. At $\mathrm{t}=1.0 \mathrm{~s}$, the reactive power absorption by the intermittent renewable source was reduced from 467 VAr down to 110 VAr. Without any voltage control, the load voltage increases from the nominal value of $216 \mathrm{~V}$ up to $224 \mathrm{~V}$ as shown by Fig. 3(a) \& (b). Both STATCOM and ES are able to restore the voltage across the critical load back to the nominal value as shown by the overlapping blue and red traces in Fig. 3(b). The ES achieves this by injecting about 115 $\mathrm{V}$ in series with the non-critical load the voltage across which drops to about $185 \mathrm{~V}$ as shown by the blue traces in Fig. 3(c). In order to suppress the voltage, both ES and STATCOM absorbs reactive power (as indicated by positive sign of $\mathrm{Q}$ ) from the system as shown in Fig. 3(d) with ES requiring to absorb about 100 VAr more than the STATCOM. (a)

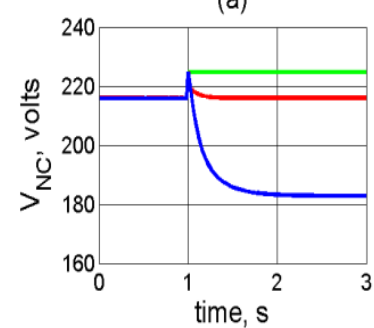

(c)

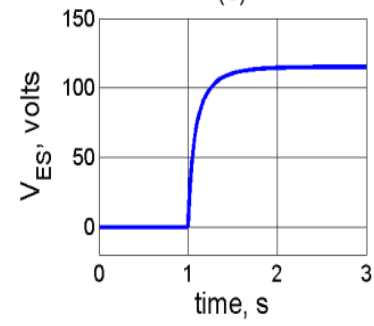

(b)

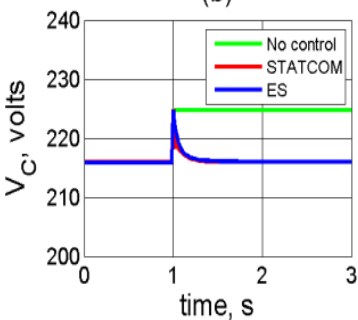

(d)

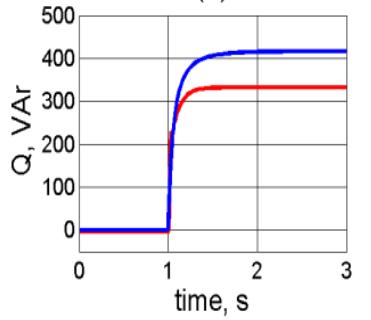

Fig. 3. System response following decrease in reactive power consumption of the intermittent source from 467 to $110 \mathrm{VAr}$

It is observed that the reactive power consumed by ES to restore the critical load voltage to normal value is higher than the reactive power consumed by STATCOM to achieve the same voltage. This can be explained from Fig. 1. An increase 
in ES voltage will result in a decrease in non-critical load voltage. This causes a decrease in the active power consumption of the (resistive) non-critical load. In order to have a higher overall active/reactive power consumption for the smart load, ES has to consume more reactive power. Note that the $X / R$ ratio is not large (about 2) in this case which is why both active and reactive power affects the voltage regulation.

\section{C.Voltage Support Mode}

To investigate the opposite effect of what was described in the previous subsection, the voltage across the loads was reduced by increasing the reactive power absorption of the renewable source. This is to test the ability of an ES and a STATCOM to support the voltage and regulate it at the nominal value. At $\mathrm{t}=1.0 \mathrm{~s}$, the reactive power absorption by the intermittent renewable source was increased from $467 \mathrm{VAr}$ to $1100 \mathrm{VAr}$. Without any voltage control, the load voltage is seen to drop from the nominal value of $216 \mathrm{~V}$ to slightly below $190 \mathrm{~V}$ as shown by the green trace in Fig. 4(a)\&(b). (a)

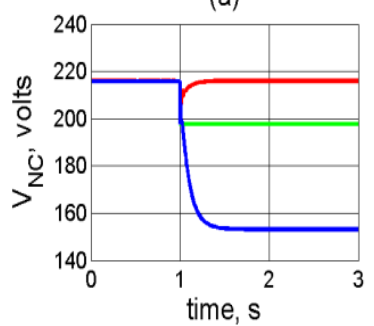

(c)

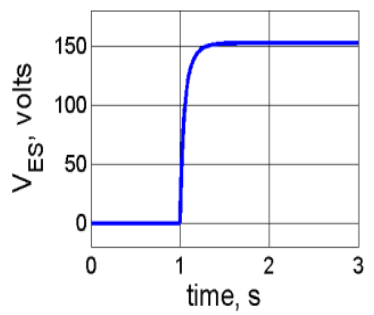

(b)

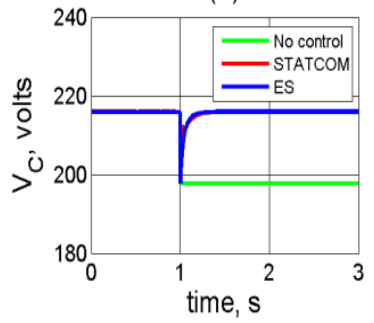

(d)

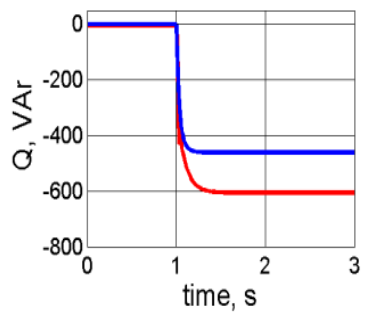

Fig. 4. System response following increase in reactive power consumption of the intermittent source from 1100 to $467 \mathrm{VAr}$.

As before, both STATCOM and ES are able to restore the voltage across the critical load back to the nominal value as shown by the overlapping blue and red traces in Fig. 4(b). The ES achieves this by injecting about $150 \mathrm{~V}$ in series with the non-critical load the voltage across which drops to about 150 $\mathrm{V}$ as shown by the blue traces in Fig. 4(a)\&(c). In order to suppress the voltage, both ES and STATCOM injects reactive power (as indicated by negative sign of Q) into the system as shown in Fig. 4(d) with ES requiring to inject about $150 \mathrm{VAr}$ less than the STATCOM. This is due to the fact that an increase in ES voltage will result in a reduction of non-critical load voltage which causes a decrease in active power consumption of the (resistive) non-critical load. Hence, the ES needs to produce less reactive power than an equivalent STATCOM to restore the system voltage due to the similar arguments about the $\mathrm{X} / \mathrm{R}$ ratio as mentioned earlier for the voltage suppress case.

\section{D.Proportion of Critical and Non-critical Loads}

An ES injects a voltage is series with the non-critical load in order to regulate the voltage across the critical load. The proportion of the critical and non-critical load is therefore, quite important towards the effectiveness of an ES both in terms of its voltage regulation capability and also the amount of reactive power (and hence its rating) exchanged with the system. The reactive capability of an ES is governed by the product of the voltage it injects and the current flowing through it (which is the same as the current through the noncritical load). If the injected voltage increases, the voltage across the non-critical load and hence the current reduces which limits the reactive capability of an ES and thus its ability to regulate the voltage across the critical load.

For low proportion of non-critical load, the fidelity of current is restricted which limits the capability of an ES compared to the case when the proportion of non-critical load is relatively high. To verify this, simulations were conducted with different proportions of non-critical (NC) and critical (C) loads. The results are shown in Fig. 5. (a)

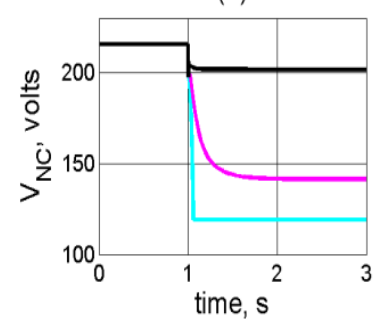

(c)

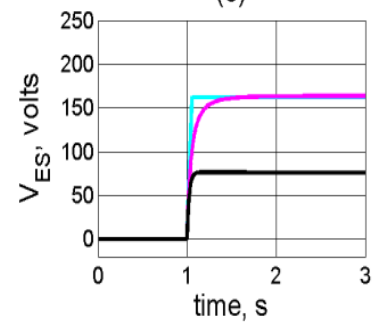

(b)

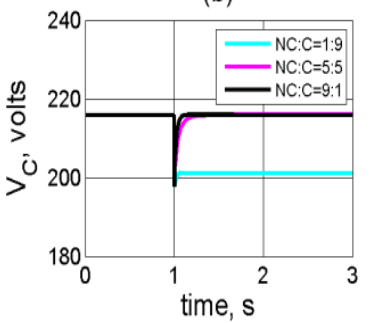

(d)

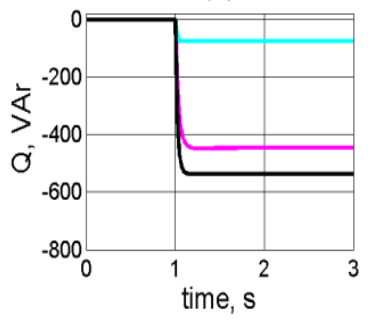

Fig. 5. System response for different distribution of non-critical and critical loads (NC:C). Disturbance is increase in reactive power consumption of the intermittent source from 467 to $1100 \mathrm{VAr}$.

It can be seen that for high proportion of non-critical load (NC:C=9:1) shown by the black traces, the critical load voltage is restored back to its nominal value, with only $80 \mathrm{~V}$ injected by the ES. This results in little change (from $216 \mathrm{~V}$ to $202 \mathrm{~V}$ ) in voltage across the non-critical load. Voltage regulation is similar for equal proportion of critical and noncritical (NC:C=5:5) loads shown by magenta traces. However, the voltage across the non-critical load is lower (about $140 \mathrm{~V}$ ) than before due to larger injected voltage $(160 \mathrm{~V})$ by the ES. Based on public statistics in Hong Kong [14], about $50 \%$ of loads (such as heaters, air-conditioners etc.) in domestics and commercial buildings can be considered as non-critical.

For low proportion of non-critical load ( $\mathrm{NC}: \mathrm{C}=1: 9)$, it is not possible to restore the voltage across the critical load back to its nominal value as shown by the cyan trace in Fig. 5(b). This is because of the low fidelity in current which restricts the reactive capability of the ES to less than $100 \mathrm{VAr}$ (Fig. 5(d)) for a maximum possible $\mathrm{ES}$ voltage of $160 \mathrm{~V}$. This 
demonstrates that the voltage regulation capability of an ES is dependent on the relative proportion of non-critical and critical load. Lesser the proportion of non-critical load, lower is the voltage regulation capability of an ES. As the second generation of ES with embedded energy storage [15] has emerged, there would be more flexibility in control which would be demonstrated in a future paper.

The reactive power exchange with the ES depends on the injected voltage $V_{E S}$ and also on the impedance of the noncritical load. Consider the circuit shown in Fig. 1. For a resistive-inductive $(R-L)$ type non-critical load with impedance $Z_{N C} \angle \theta_{N C}$, the voltages $V_{C}, V_{E S}$ and $V_{N C}$ are shown on the phasor diagram in Fig. 6(a) when the ES is working in voltage support (i.e. capacitive) mode. From the phasor diagram we can write:

$$
\begin{aligned}
& V_{C}^{2}=\left(V_{N C}-V_{E S} \sin \theta_{N C}\right)^{2}+\left(V_{E S} \cos \theta_{N C}\right)^{2} \\
& V_{N C}= \pm \sqrt{V_{C}^{2}-\left(V_{E S} \cos \theta_{N C}\right)^{2}}+V_{E S} \sin \theta_{N C} \\
& Q_{E S}=V_{E S} I_{N C} \sin \left(-90^{\circ}\right)=-V_{E S} I_{N C}=-\frac{V_{E S} V_{N C}}{Z_{N C}} \\
& Q_{N C}=V_{N C} I_{N C} \sin \theta_{N C}=\frac{V_{N C}^{2}}{Z_{N C}} \sin \theta_{N C}
\end{aligned}
$$

Here, $Q_{E S}$ and $Q_{N C}$ are the reactive powers of the ES and the non-critical load, respectively. For a purely resistive noncritical load, the reactive power of the ES and the smart load will be equal. However, they would be different if the the noncritical is not purely resistive. If the ES is working in voltage support (i.e. capacitive) mode with a non-critical load of $R-L$ type, the total reactive power of the smart load $Q_{S L}$ is given by:

$$
\begin{gathered}
Q_{S L}=Q_{E S}+Q_{N C} \\
Q_{S L}=\frac{-V_{E S}\left( \pm \sqrt{V_{C}^{2}-\left(V_{E S} \cos \theta_{N C}\right)^{2}}+V_{E S} \sin \theta_{N C}\right)}{Z_{N C}} \\
+\frac{\left( \pm \sqrt{V_{C}^{2}-\left(V_{E S} \cos \theta_{N C}\right)^{2}}+V_{E S} \sin \theta_{N C}\right)^{2}}{Z_{N C}} \sin \theta_{N C}
\end{gathered}
$$

Similarly, for the ES in voltage suppress (i.e. inductive) mode, we can write:

$$
V_{N C}= \pm \sqrt{V_{C}^{2}-\left(V_{E S} \cos \theta_{N C}\right)^{2}}-V_{E S} \sin \theta_{N C}
$$

and

$$
\begin{aligned}
& Q_{S L}=\frac{V_{E S}\left( \pm \sqrt{V_{C}^{2}-\left(V_{E S} \cos \theta_{N C}\right)^{2}}-V_{E S} \sin \theta_{N C}\right)}{Z_{N C}} \\
& +\frac{\left( \pm \sqrt{V_{C}^{2}-\left(V_{E S} \cos \theta_{N C}\right)^{2}}-V_{E S} \sin \theta_{N C}\right)^{2}}{Z_{N C}} \sin \theta_{N C}
\end{aligned}
$$

From (3), (6) and (8) it is clear that the reactive power of the ES and the smart load are both dependent on non-critical load impedance $\left(Z_{N C}\right)$. A decrease in the value of $Z_{N C}$ (increase in the non-critical load) will result in an increase in reactive power. Hence, a higher proportion of non-critical load will increase the effectiveness of an ES.

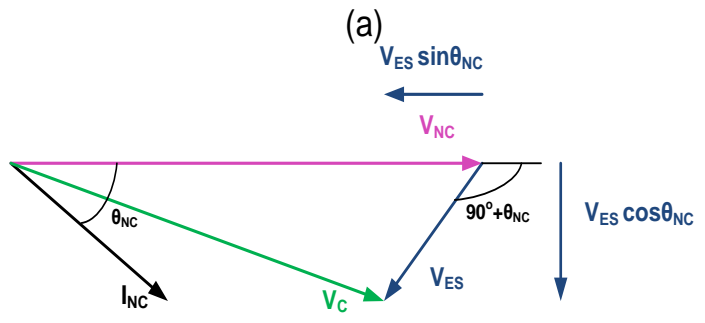

(b)

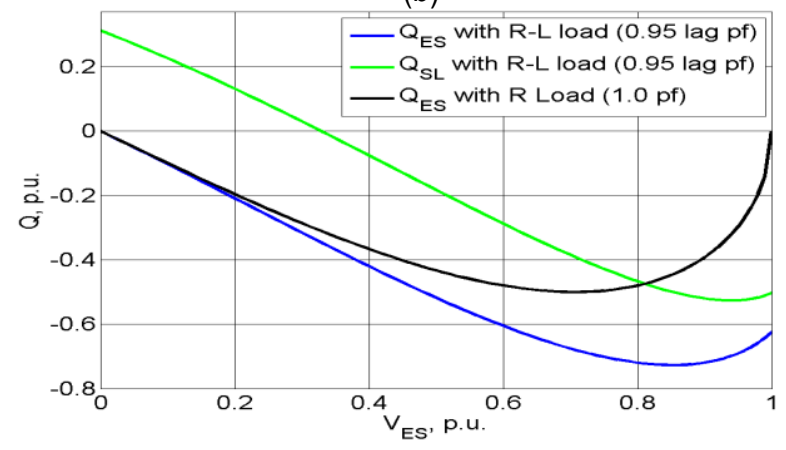

Fig. 6. (a) Phasor diagram showing relationship between voltages across non-critical load, critical load and ES, (b) Variation of reactive power of ES and smart load with respect to ES voltage for $R-L$ and $R$ non-critical loads.

\section{E.Reactive Power Limit of Smart Load}

For a fixed non-critical load impedance $\left(Z_{N C} \angle \theta_{N C}\right)$ and a target critical load voltage $\left(V_{C}=1.0\right.$ p.u.), all the terms on the right hand side of (3), (6) and (8) are constant except the ES voltage $\left(V_{E S}\right)$. Hence, $Q_{E S}$ and $Q_{S L}$ can be expressed as functions of $V_{E S}$ only. Fig. 6(b) shows the variation of $Q_{E S}$ and $Q_{S L}$ versus $V_{E S}$ for $V_{C}=1.0$ p.u., and $Z_{N C}=1.0$ p.u. for two different power factor of the non-critical load. In all cases the ES is considered to be in voltage support (i.e. capacitive) mode as indicated by the negative sign of $Q_{E S}$. For a purely resistive non-critical load, $Q_{E S}$ and $Q_{S L}$ are equal and are shown by the black trace in Fig. 6(b). $Q_{E S}$ and $Q_{S L}$ for an $R-L$ non-critical load with 0.95 power factor are shown by blue and green traces respectively. The figure is drawn only for nonnegative values of $V_{N C}$ phasor represented by (2).

It can be seen that beyond a certain point, increasing the ES voltage will result in a decrease in reactive power magnitude due to decrease of the current. Hence, it is essential to impose a limit on the output of the PI controller which determines the ES voltage magnitude, so that the voltage injected by the ES does not go beyond the maximum reactive power (magnitude) point on the curves shown in Fig. 6(b). It may also be noted that the maximum values of the two reactive powers will occur at different values of $V_{E S}$ if the noncritical load is not purely resistive. In such cases, the limits of the PI controller should be based on the maximum value of $Q_{S L}$. Also, it can also be seen that the reactive power output of the smart loads would be maximum at different values of $V_{E S}$ depending on the power factor of the non-critical loads. 


\section{F. Variable Active and Reactive Power from Renewable Source}

In this subsection, the result of varying the reactive power absorbed and the active power generated by the renewable energy source connected at bus 2 (see Fig. 2) is shown. First, the reactive power absorbed is varied between 150 and 1100 VAr keeping the active power generation fixed at zero. Without any voltage control, the voltage across the loads reduces as the reactive power absorption increases. This is shown by the green trace in Fig. 7(a) about the nominal voltage of $216 \mathrm{~V}$. For Q<467 VAr, the actual voltage is higher than nominal requiring voltage suppression while for Q>467 VAr, the actual voltage is less than the nominal requiring voltage support.

(a)

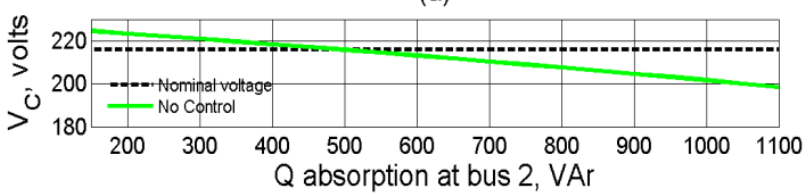

(b)

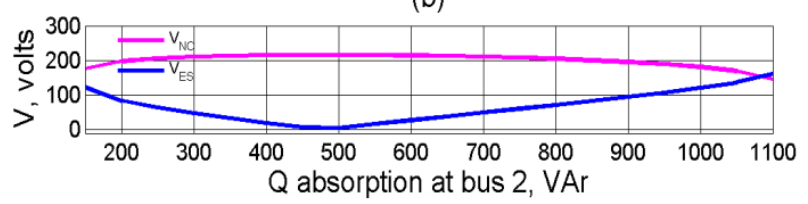

(c)

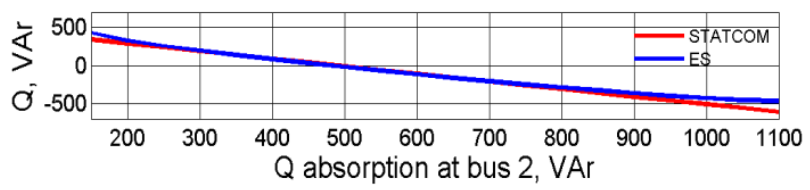

Fig. 7. Variation of voltages across the critical and non-critical loads and voltage and reactive power of electric spring as the reactive power absorption by the renewable source (at bus 2, Fig. 2) is changed from $150 \mathrm{VAr}$ to 1100 VAr.

Voltage injected by the ES and the voltage across the noncritical load are shown in Fig. 7(b). For $\mathrm{Q}=467 \mathrm{VAr}$, the voltage injected by the ES is almost zero while the voltage across the non-critical load is equal to the nominal value of $216 \mathrm{~V}$. On either side of $\mathrm{Q}=467 \mathrm{VAr}$, the ES injects a positive voltage, resulting in a reduced voltage across the non-critical load such that the vector sum of the two equals the nominal voltage (i.e. $216 \mathrm{~V}$ ) which is maintained across the critical load.

The reactive power exchanged by the ES is compared against that of a STATCOM to regulate the critical load voltage at $216 \mathrm{~V}$. It can be seen that for voltage suppression ( $Q<467$ VAr), both of the ES and STATCOM absorbs VAr from the system (as indicated by the positive sign) while for voltage support ( $\mathrm{Q}>467 \mathrm{VAr})$ they inject VAr into the system.

It should be noted that over the range of variation of $\mathrm{Q}$ absorption shown in Fig. 7(c), the reactive power exchanged by the ES and the STATCOM are very similar. For higher levels of voltage support (Q>900 VAr), a STATCOM requires more reactive power than an ES with the difference between the two growing for larger $\mathrm{Q}$ absorption. For higher levels of voltage suppression $(\mathrm{Q}<200 \mathrm{VAr})$ on the other hand, ES is seen to require more $\mathrm{Q}$ than STATCOM. This is due to the change in power consumption of the non-critical load (when ES is active) as explained earlier in Sections II.B and II.C.

Next, the reactive power absorption is fixed at $\mathrm{Q}=467$ $\mathrm{VAr}$, while the active power $(\mathrm{P})$ generated at bus 2 is varied from 0 to $900 \mathrm{~W}$. Without any voltage control, the voltage across the loads increases with increase in active power generation $(\mathrm{P})$ at bus 2 as shown by the green trace in Fig. 8(a).

One important point to note from Fig. 8(b) is that as power generation from the renewable source at bus 2 increases, the voltage across the non-critical load (and hence the active power consumed by it) reduces in order to regulate the voltage across the critical load to its nominal value of $216 \mathrm{~V}$. In such cases, the non-critical load voltage has to be lower than its nominal value for a non-zero ES voltage. Hence the active power consumed by the non-critical load cannot increase above its nominal value. This restriction can be overcome if the load has non-unity power factor in which case the two voltages are not constrained to be in quadrature. Alternatively, the ES can be allowed to inject a voltage with any phase angle (not just \pm 90 degrees) with respect to the current requiring exchange of both active and reactive power with the system which is possible through incorporation of energy storage (i.e. a battery) into the ES. This type of ES with embedded energy storage is more versatile in terms of its capability to control the voltage while ensuring power balance and hence regulate the system frequency and is referred to as version 2 or generation 2 of ES (ESv2) [15]. The scope of this paper is limited to reactive power only version (ESv1) [5] to ensure a fair comparison against STATCOM which only exchanges reactive power with the system.

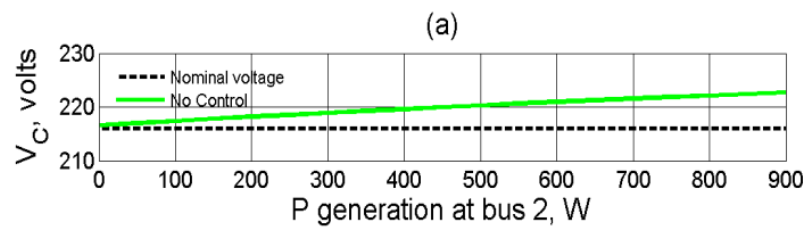

(b)

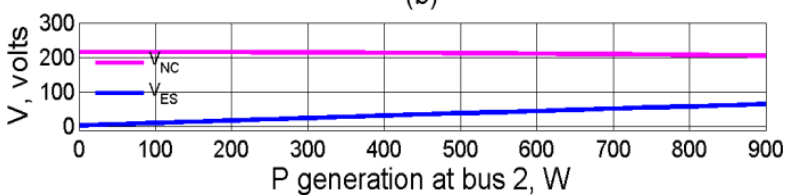

(c)

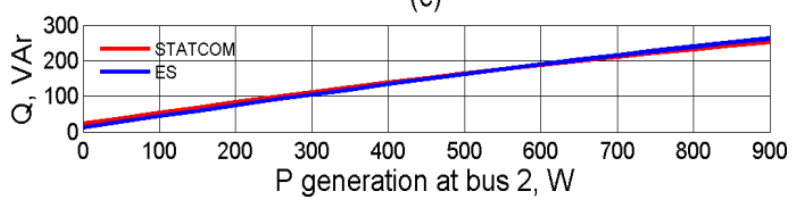

Fig. 8. Variation of voltages across the critical and non-critical loads and voltage and reactive power of electric spring as the active power generation by the renewable source (at bus 2, Fig. 2) is changed from 0 to $900 \mathrm{~W}$.

\section{IV.CASE STUdy 1: IEEE 13 Node TeST FeEDER}

\section{A. Test Network}

After comparing the performance of a single ES against a STATCOM, the focus was on collective action of a group of distributed ESs and how that compares against a single STATCOM. To investigate this, the IEEE 13-bus test feeder 
system shown in Fig. 9 was considered [16]. The network has two voltage levels $4.16 \mathrm{kV}$ and $480 \mathrm{~V}$ with a distribution transformer connected between node 633 and 634 .

In the original IEEE 13-node test feeder, the LV side is represented by an aggregated load at bus 634 . For the purpose of this study, the LV side was modified to distribute the total load (160 kW with 0.825 lagging power factor) among four newly introduced LV bus bars labeled as 1, 2, 3 and 4 . The aggregated load $(160 \mathrm{~kW})$ connected at node 634 was split equally among these four new nodes. The ratio of critical to non-critical loads was assumed to be 50:50. The LV distribution line conductor dimensions were chosen based on the current ratings of the loads and the conductor data and the distance between the LV bus bars are provided in the Appendix. All other circuit parameters are exactly the same as feeder is set up to study unbalanced operation. For this study we considered only one phase of the system as unbalance operation is not the focus here.

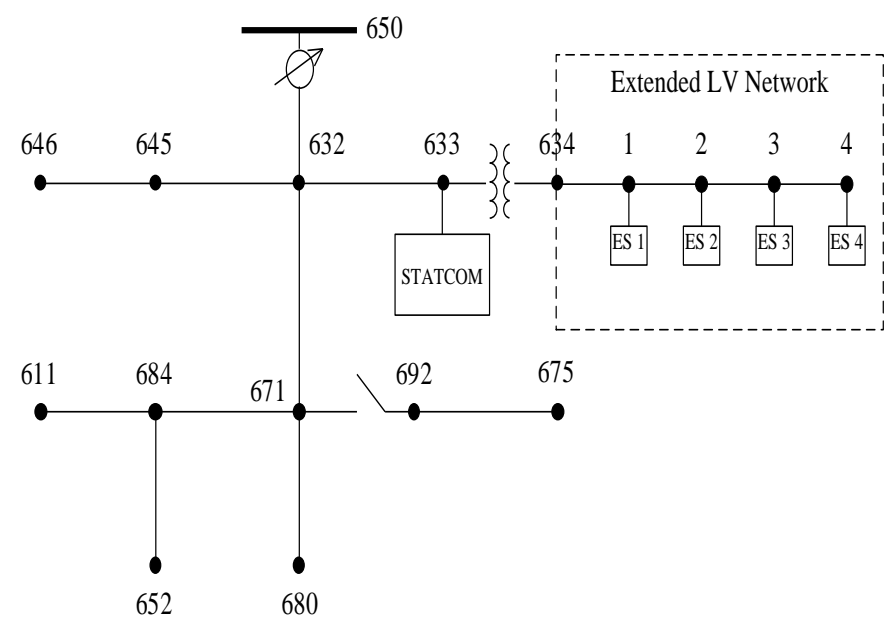

Fig. 9. IEEE 13 node test feeder network with distributed representation of the $\mathrm{LV}$ side.

\section{B. Voltage Support Mode}

The collective action of the distributed ESs was compared with a STATCOM installed on the MV side at bus 633. A 5\% step reduction in the source voltage at bus 650 was considered. The comparison is based on the total reactive power required by the 4 ESs in order to achieve an acceptable voltage regulation at the LV buses. Voltage regulation at a particular bus is defined in (9) as the normalized difference between the rated voltage (1.0 p.u) and the actual voltage in the event of a voltage disturbance.

$$
\text { Voltage Regulation }=\frac{\left|V_{\text {rated }}-V_{\text {actual }}\right|}{V_{\text {rated }}} \times 100 \%
$$

The voltage regulation achieved at different LV buses is shown in Fig. 10. Without any voltage compensation the voltage regulation becomes progressively poorer away from the MV bus (bus 633) due to the voltage drop in the LV feeder. In this case the voltage regulation turns out to be unacceptably high $(>5 \%)$. With a STACOM providing 'perfect' (0) voltage regulation at bus 633 , the voltages at the LV bus bars are regulated within the acceptable limit (5\%).
Nonetheless the regulation gets poorer away from the STATCOM location. With ESs the voltage regulation is more uniform across the LV feeder. A degree of voltage regulation can still be ensured even if one or more ES are out of operation. In order to demonstrate this qualitatively, the ES connected with Bus 4 was deactivated. It can be seen that the voltage regulation is still better than having no control at all, but understandably worse than that with a STATCOM. There are only four ESs in this system. In a larger system, we can have multiple ESs deactivated without making the system prone to voltage changes.

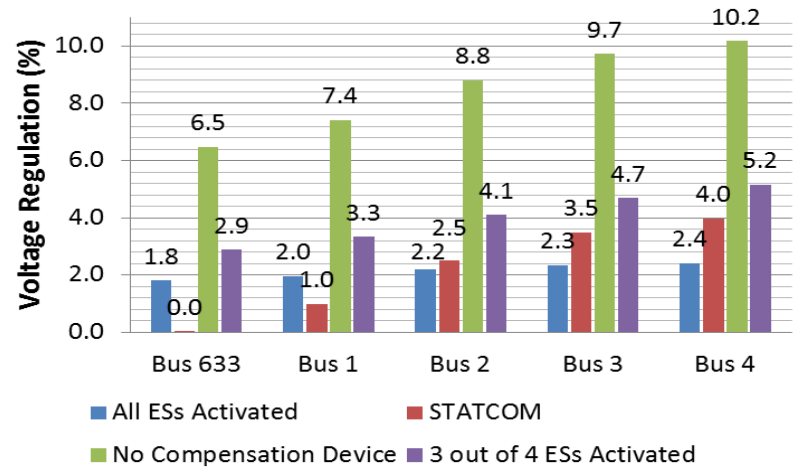

Fig. 10. Voltage regulation with distributed ESs and STATCOM following $5 \%$ reduction of the source voltage at bus 650 .

The overall voltage regulation achieved in each case is compared in terms of the root mean square of the deviation of the actual voltages from the rated (1.0 p.u) values which is termed as total voltage regulation and defined in (10).

$$
\begin{aligned}
& \text { Total Voltage Regulation } \\
& =\sqrt{\frac{\sum_{i=1}^{N b}\left(V_{\text {rated_(p.u. } \left.){ }^{-V} \text { actual__(p.u. }\right)}\right)^{2}}{N b}}
\end{aligned}
$$

where, $\mathrm{Nb}$ is the total number of buses where voltage regulation is considered. The results are shown in Fig. 11 for both voltage support and voltage suppress (discussed in next subsection) modes. It can be seen that the group of ESs achieves better voltage regulation than a STATCOM at bus 633 (Fig. 11(b)). Moreover, the total reactive capacity required for the ESs is about six times less than that required by the STATCOM (Fig. 11(a)).

\section{Voltage Suppress Mode}

Similar exercise, as in the previous subsection, was repeated for over-voltage (voltage suppress) condition. A 5\% step increase in the source voltage at bus 650 was simulated. The voltage regulations with ESs and STATCOM are shown in Fig. 12. As before, voltage regulation with STATCOM gets worse away from its connection point.

Without any voltage compensation, the voltage regulation is better away from the MV bus (bus 633) due to the natural voltage drop across the LV feeder. With a group of ESs, the voltage regulation is more uniform which results in less than half of the total voltage regulation achieved with a STATCOM as shown in Fig. 11(b). 
Moreover, the total reactive power consumption by the ESs is less than twenty times that of a STATCOM. Thus, for both under-voltage and over-voltage conditions, a group of distributed ESs is shown to achieve better total voltage regulation than a STATCOM with a total reactive capacity much less than that of STATCOM (Fig. 11(a)).

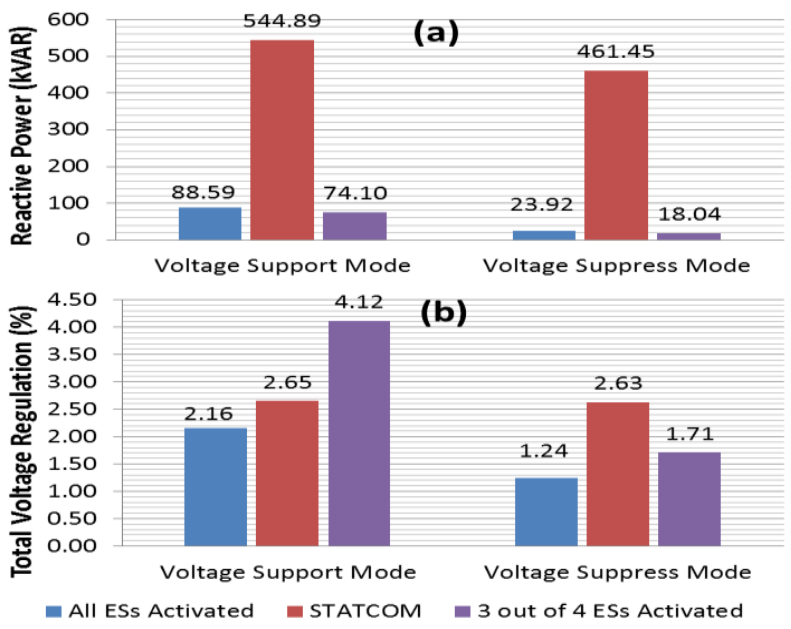

Fig. 11. Reactive power required and total voltage regulation achieved collectively by all the distributed ESs and STATCOM under voltage support and suppress condition.

The study on the modified IEEE 13 node test feeder network confirms the following:

1. Better total voltage regulation is achieved with a group of distributed ESs compared to a STATCOM although both are able to ensure acceptable regulation.

2. Total reactive capacity required by the group of ESs is significantly less than that of the STATCOM.

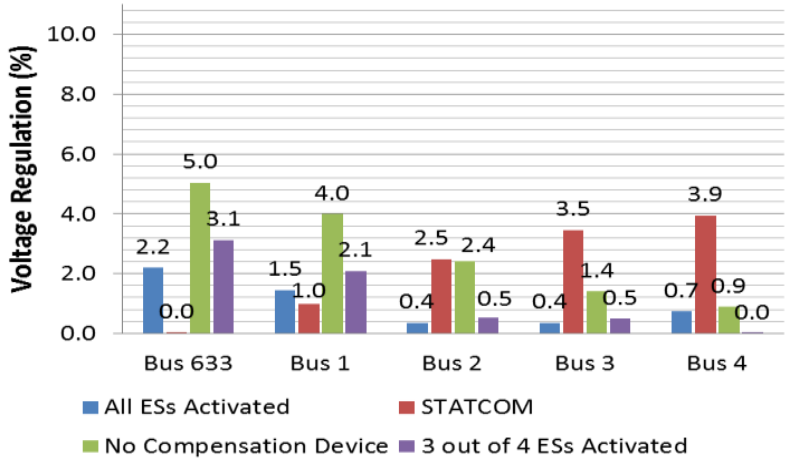

Fig. 12. Voltage regulation with distributed ESs and STATCOM following $5 \%$ increase in source voltage at bus 650 .

\section{CASE Study 2: Distribution NeTWORK IN SHa Lo WAN BAY, LANTAU ISLAND, HONG KONG}

\section{A.Test Network}

Another case study was performed on a part of the distribution network at Sha Lo Wan Bay in Lantau island of Hong Kong. The objective is to compare the voltage regulation performance of a group of ESs against a STATCOM. The $11 \mathrm{kV}$ substations and a part of the $220 \mathrm{~V}$ feeder network as shown in Fig. 13 was considered for this study.
The network data are provided in the Appendix. The parameters of the distribution lines are practical values, but the loads are arbitrarily set because the actual load data are confidential due to privacy policy. There are 23 purely resistive loads connected to the $220 \mathrm{~V}$ network. Each load has a rating of $30 \mathrm{~kW}$ which was assumed to have a 50:50 split between critical and non-critical load. An ES was connected in series with each of the 23 non-critical loads.

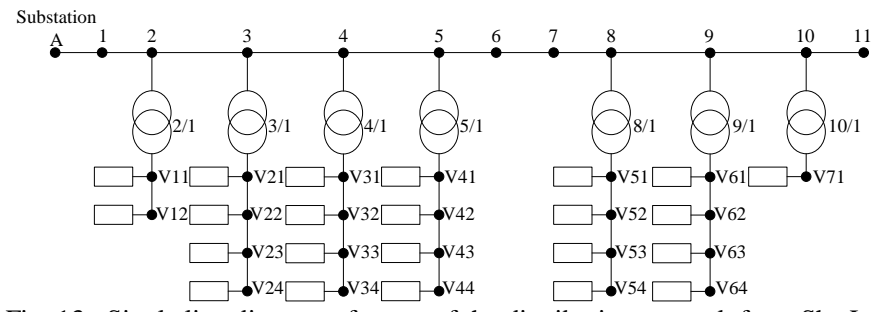

Fig. 13. Single line diagram of a part of the distribution network from Sha Lo Wan bay, Lantau Island, Hong Kong.

\section{B. Voltage Support Mode}

To validate the collective performance of the ESs and compare it with the voltage control of a STATCOM, a 5\% step reduction in the $11 \mathrm{kV}$ substation (substation A) voltage was simulated. Voltages at all the load connection points across the distribution network at Sha Lo Wan Bay (shown in Fig. 13) were monitored.

The three subplots in Fig. 14 correspond to the cases with no voltage compensation, with a STATCOM regulating the voltage at the $11 \mathrm{kV}$ substation (substation A) and ESs connected in series with all the non-critical loads at $220 \mathrm{~V}$ level. The distribution of voltage is shown in Fig. 14 along the $11 \mathrm{kV}$ feeder (x-axis) and also along each of the $220 \mathrm{~V}$ feeders (y-axis). Without any voltage compensation (Fig. 14(a)) the voltage regulation is poor $(>5 \%)$ getting worse as we move further away along the $11 \mathrm{kV}$ feeder and also the $220 \mathrm{~V}$ feeders due to natural voltage drop in the lines.

The STATCOM regulates the voltage at substation A which results in very good regulation at bus 1 (Fig. 14(b)). However, the voltage regulation is poorer (but much better than the case without voltage compensation) further away along the $11 \mathrm{kV}$ and $220 \mathrm{~V}$ feeders.

In the case with ESs, the voltage regulation turned out to be better, especially at the loads which are at the far ends of the $220 \mathrm{~V}$ feeder. As the ES regulates the voltage by manipulating the voltage drop across the supply impedance, larger impedance (for distant loads) improves the effectiveness of ESs which is apparent from Fig. 14(c).

The distribution of the voltage across all the load buses of Sha Lo Wan Bay distribution system is captured in terms of their mean and standard deviation in Fig. 15 for voltage support and voltage suppress modes (discussed in the next subsection). For voltage support mode, the distributed ESs provide much better (lower average) and tighter (lower standard deviation) voltage regulation than a STATCOM (Fig. 15(a)).

This is further substantiated by the total voltage regulation shown in Fig. 16(b) which shows ESs achieve 3 times better total regulation than a STATCOM. Moreover, the total reactive power capability required for the group of ESs is 
about 14 times less than that of the STATCOM as shown in Fig. 16(a).

(a)

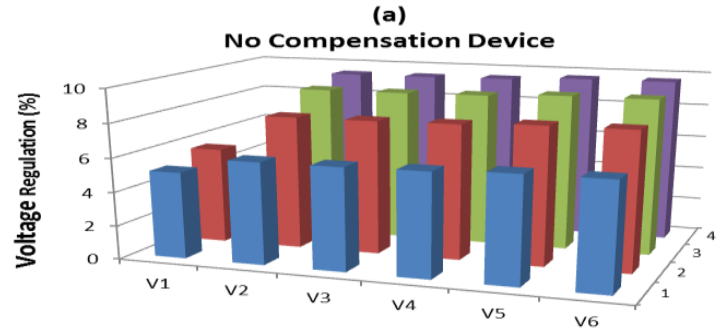

(b)

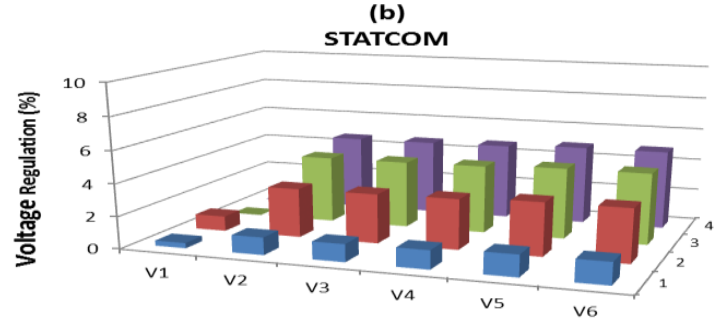

(c)

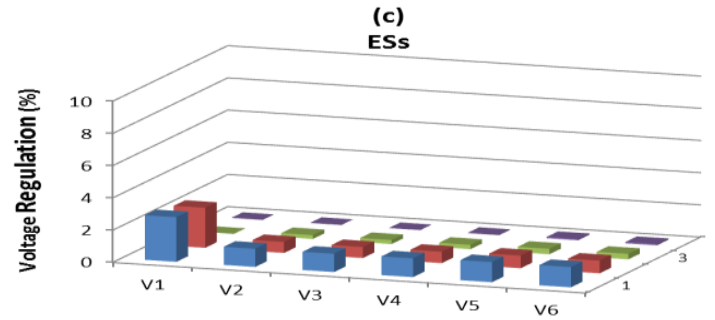

Fig. 14. Voltage regulation with distributed ESs and STATCOM following $5 \%$ reduction in source voltage at substation A.

\section{C.Voltage Suppress Mode}

Similar exercise as above was conducted to compare the collective performance of the ESs and a STATCOM under voltage suppress mode. A 5\% step increase in the $11 \mathrm{kV}$ substation voltage was simulated. The voltage regulation performance is shown in Fig. 15(b) in terms of the mean and standard deviation of the voltages at all the load buses.

It can be seen that voltage regulation without any voltage compensation is within the acceptable (5\%) limits. In this case the voltage regulation actually gets better away from the 11 $\mathrm{kV}$ bus (substation $\mathrm{A}$ ) due to the natural voltage drop across the $11 \mathrm{kV}$ and $220 \mathrm{~V}$ feeders. Similar to the voltage support mode, ESs provide much better (lower average) and tighter (lower standard deviation) voltage regulation than a STATCOM.

The total voltage regulation shown in Fig. 16(b) depicts that the group of ESs achieve about 2 times better total regulation than a STATCOM. The total reactive power capability required for the group of ESs (Fig. 16(a)) is about 30 times less than that of the STATCOM.

The above case study on the Sha Lo Wan Bay distribution network in Hong Kong demonstrates the effectiveness of distributed voltage control through a group of ESs under both voltage support and suppresses modes. A group of distributed ESs achieves much better total voltage regulation compared to a STATCOM with much less reactive capability.
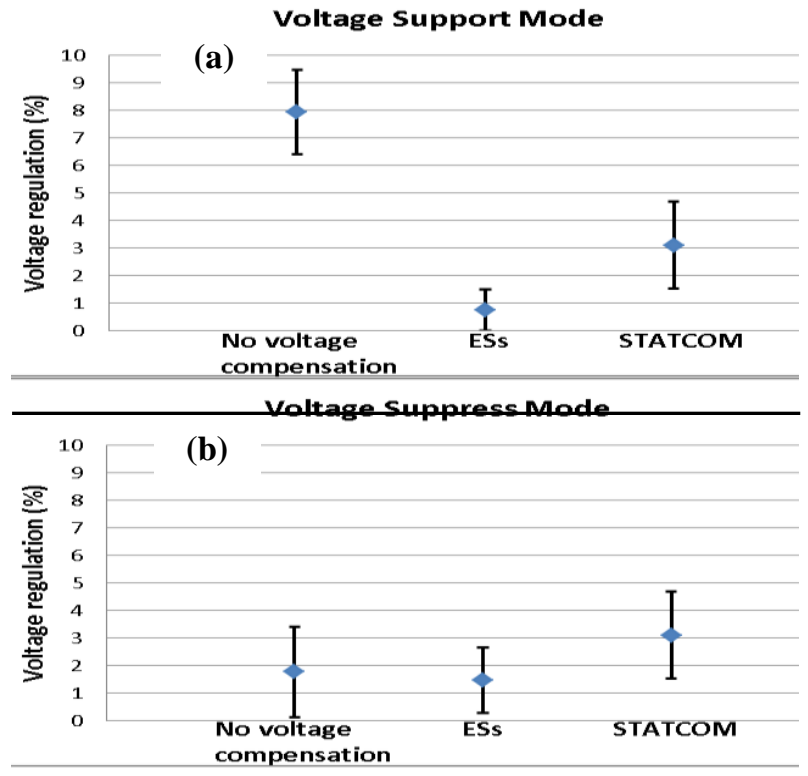

Fig. 15. Voltage distribution at different parts of the Sha Lo Wan distribution network under voltage support and suppress modes.

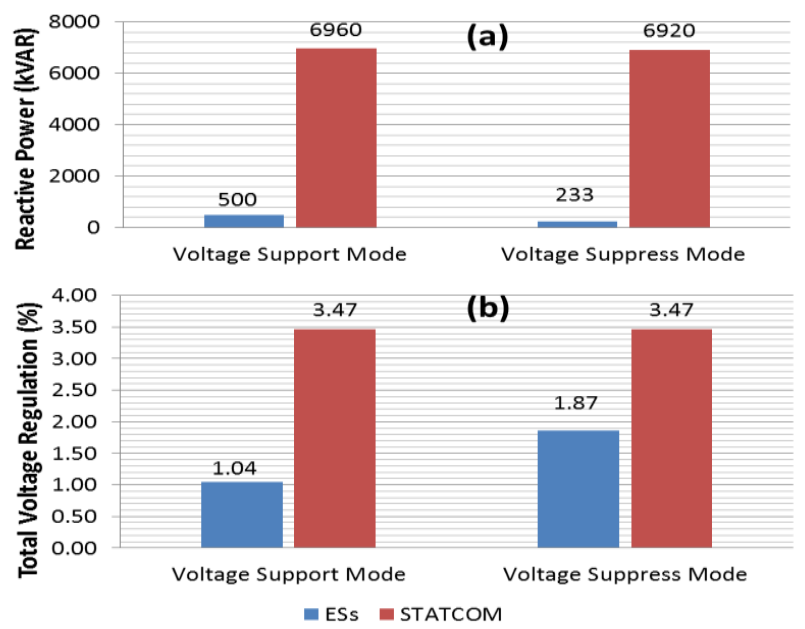

Fig. 16. Reactive power required and total voltage regulation achieved collectively by all the distributed ESs and the STATCOM under voltage support and suppress condition.

\section{V.DISCUSSIONS}

The case studies presented in this paper confirms the following:

1. A group of distributed ESs is able to achieve better voltage regulation than a STATCOM. The reactive power capacity of a STATCOM is not limited until the current limits are violated. In principle, a STATCOM can inject any amount of current (within its rated capacity) and thus, any amount of reactive power. On the contrary, the reactive power capacity of an ES is limited. As the voltage injected by an ES increases the voltage across the non-critical load and hence the current through the ES (as they are in series) decreases. At some point their product, which is the reactive power reaches the maximum beyond which the ES cannot inject/absorb more reactive power. Hence, its voltage regulation capability is limited. However, if there are 
multiple ESs distributed in the system, they can share the burden and this would not necessarily be a problem. The capability of ESs to regulate the voltage also depends on the relative proportion of critical and non-critical loads. Higher proportion of non-critical loads allows larger fidelity on the current and hence improves the voltage regulation capability.

2.In general, it is easier to regulate the voltage at locations which are electrically farther away from a stiff voltage source which in this case would be the upstream MV/HV network. As the ESs are located farther away from the upstream MV network than a STATCOM, there is less burden on the ESs and collectively, they require less reactive power than a STATCOM installed upstream. This can be explained analytically by considering a simple circuit shown in Fig. 17.

An inductive load $\left(Z_{L} \angle \theta_{L}\right)$ is supplied from an ideal voltage source though a series impedance $\left(Z_{S} \angle \theta_{S}\right)$ representing a feeder. A reactive power compensation device is connected in parallel to regulate the load voltage $\left(V_{L} \angle 0\right)$ to the nominal value in case fluctuations in the source voltage $\left(V_{S}\right)$. If $I_{C} \angle \theta_{C}$ is the current injected by the compensation device, the load voltage (considered as the reference) can be expressed as:

$$
V_{L} \angle 0=V_{S} \angle \delta \frac{Z_{L} \angle \theta_{L}}{Z_{L} \angle \theta_{L}+Z_{S} \angle \theta_{S}}+I_{C} \angle \theta_{C}\left(Z_{L} \angle \theta_{L} \| Z_{S} \angle \theta_{S}\right)
$$

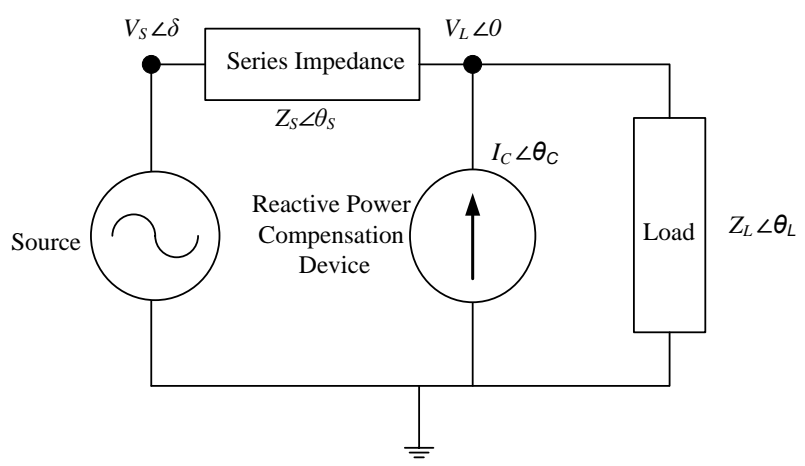

Fig. 17. A simple circuit showing an ideal source connected with a fixed impedance load through some series impedance and a voltage compensation device in parallel to the load.

In power systems, the series impedance is typically much lower compared to the load impedance $\left(Z_{L}>Z_{S}\right)$. Under normal operation, the voltage across the load impedance is between 0.95-1.05 p.u. while the voltage drop across the series impedance varies in the range of $\pm 0.05-0.10$ p.u. Hence, the following approximation is valid without introducing much error.

$$
\left(Z_{L} \angle \theta_{L}+Z_{S} \angle \theta_{S}\right) \approx Z_{L} \angle \theta_{L}
$$

From (11) and (12), we can write:

$$
\begin{aligned}
& V_{L} \angle 0 \approx V_{S} \angle \delta+I_{C} \angle \theta_{C}\left(Z_{S} \angle \theta_{S}\right) \\
& I_{C} \angle \theta_{C} \approx \frac{V_{L} \angle 0-V_{S} \angle \delta}{\left(Z_{S} \angle \theta_{S}\right)}
\end{aligned}
$$

The phase angle $\theta_{C}$ will be either $90^{\circ}$ or $-90^{\circ}$ depending on the type of reactive power compensation required (inductive or capacitive). The phase angle $\theta_{S}$ is constant for a given $X / R$ ratio of the feeder. From (14) it is evident that the magnitude of the compensation current $\left(I_{C}\right)$ required to restore the load voltage $\left(V_{L}\right)$ back to the nominal value, in case of a change in source voltage magnitude $\left(V_{S}\right)$, is inversely proportional to the source impedance $\left(Z_{S}\right)$. For a given change in source voltage, a higher series impedance magnitude (for longer distance away from the source) will require a smaller compensation current (which implies less reactive power) to restore the critical load voltage. Therefore, the farther the load is from the voltage source, the easier it is to regulate the voltage with a less reactive power exchange.

3. A STATCOM regulates the voltage at the point of connection but the load buses downstream will still have a natural voltage profile where the voltage at far end could still be low even if the voltage at STATCOM bus is regulated at 1.0 p.u. On the contrary, a group of distributed ESs with droop control also improves the voltages at the far end resulting in a better total voltage regulation.

4. STATCOMs do central voltage control typically at the point of coupling with the MV/LV feeders. So the entire downstream feeders are vulnerable to voltage problems if the STATCOM is out of operation. The ESs provide distributed voltage control, and failure of one/two does not make the entire feeder system susceptible to voltage problems.

5 . For an $R-L$ type non-critical load, better voltage regulation could be achieved in voltage suppress mode as both ES (working in inductive mode) and the non-critical load consume inductive reactive power and thereby, aid each other. Same is true for voltage support mode (ES in capacitive mode) in case of an $R-C$ type non-critical load. In voltage support mode with an $R-L$ type non-critical load, the total reactive power of the smart load is equal to the difference between the reactive power produced by the ES and that consumed by the load which reduces the voltage regulation capability compared to the case of a purely resistive load.

\section{VI.CONCLUSIONS}

In this paper a comparison is made between distributed voltage control using ES against the traditional single point control with STATCOM. For a given range of supply voltage variation, the total voltage regulation and the total reactive capacity required for each option to produce the desired voltage regulation at the point of connection are compared. A simple case study with a single ES and STATCOM is presented first to show that the ES and STATCOM require comparable reactive power to achieve similar voltage regulation. Comparison between a STATCOM and ES is further substantiated through similar case studies on the IEEE 13-bus test feeder system and also on a part of the distribution network in Sha Lo Wan Bay, Hong Kong. In both cases, it turns out that the ESs requires less overall reactive power capacity than STATCOM and yields better total voltage regulation. This makes electric springs (ESs) a promising technology for future smart grids where selective voltage 
regulation for sensitive loads would be necessary alongside demand side response.

\section{APPENDIX}

The parameters for the modified LV segment (buses 1-4) of the IEEE 13 node test feeder system are provided here.

\begin{tabular}{|l|c|c|c|c|}
\hline $\begin{array}{l}\text { Between } \\
\text { buses }\end{array}$ & kcmil & type & $\begin{array}{c}\mathbf{R}+\mathbf{j X} \\
(\boldsymbol{\Omega} / \mathbf{m i l e})\end{array}$ & $\begin{array}{c}\text { Current } \\
\text { rating (A) }\end{array}$ \\
\hline 634 to 4 & 1000 & AAC & $0.105+\mathrm{j} 0.591$ & 698 \\
\hline
\end{tabular}

\begin{tabular}{|l|c|c|c|c|}
\hline Between buses & $\mathbf{6 3 4 - 1}$ & $\mathbf{1 - 2}$ & $\mathbf{2 - 3}$ & $\mathbf{3 - 4}$ \\
\hline Distance (feet) & 50 & 100 & 100 & 100 \\
\hline
\end{tabular}

The parameters for the section of the Sha Lo Wan Bay distribution network considered for this study are given below for the $11 \mathrm{kV}$ and $220 \mathrm{~V}$ sections.

Data for $11 \mathrm{kV}$ section of Sha Lo Wan Bay network

\begin{tabular}{|c|c|c|c|c|c|}
\hline From & To & $\begin{array}{c}\text { Distance } \\
(\mathbf{m})\end{array}$ & $\begin{array}{c}\text { Cable size } \\
\left(\mathbf{m m}^{2}\right)\end{array}$ & $\begin{array}{c}\text { Overhead line } \\
\text { size }\left(\mathbf{m m}^{2}\right)\end{array}$ & $\begin{array}{c}\mathbf{R + j X} \\
(\boldsymbol{\mu} \mathbf{\Omega} / \mathbf{m})\end{array}$ \\
\hline Sub A & 2 & 600 & $2403 / \mathrm{C}$ & - & $98+\mathrm{j} 93$ \\
\hline 1 & 2 & 480 & - & 50 AAAC & $649+\mathrm{j} 335$ \\
\hline 2 & $2 / 1$ & 100 & - & 50 AAAC & $649+\mathrm{j} 335$ \\
\hline 2 & 3 & 285 & - & 50 AAAC & $649+\mathrm{j} 335$ \\
\hline 3 & $3 / 1$ & 143 & - & 50 AAAC & $649+\mathrm{j} 335$ \\
\hline 3 & 4 & 62 & - & 50 AAAC & $649+\mathrm{j} 335$ \\
\hline 4 & $4 / 1$ & 137 & - & 50 AAAC & $649+\mathrm{j} 335$ \\
\hline 4 & 5 & 280 & - & 50 AAAC & $649+\mathrm{j} 335$ \\
\hline 5 & $5 / 1$ & 163 & - & 50 AAAC & $649+\mathrm{j} 335$ \\
\hline 5 & 6 & 845 & - & 50 AAAC & $649+\mathrm{j} 335$ \\
\hline 6 & 7 & 139 & $953 / \mathrm{C} \mathrm{Cu}$ & - & $247+\mathrm{j} 122$ \\
\hline 7 & 8 & 453 & - & 50 AAAC & $649+\mathrm{j} 335$ \\
\hline 8 & $8 / 1$ & 29 & $3003 / \mathrm{C} \mathrm{Al}$ & - & $130+\mathrm{j} 87$ \\
\hline 8 & 9 & 228 & - & 50 AAAC & $649+\mathrm{j} 335$ \\
\hline 9 & $9 / 1$ & 26 & $1503 / \mathrm{C} \mathrm{Al}$ & - & $248+\mathrm{j} 82$ \\
\hline 9 & 10 & 1467 & - & 50 AAAC & $649+\mathrm{j} 335$ \\
\hline 10 & $10 /$ & 35 & - & 50 AAAC & $649+\mathrm{j} 335$ \\
\hline 10 & 11 & 466 & - & 50 AAAC & $649+\mathrm{j} 335$ \\
\hline
\end{tabular}

Data for 220V section of Sha Lo Wan Bay network

\begin{tabular}{|c|c|c|}
\hline Size / Cable type & $\begin{array}{c}\mathbf{R}+\mathbf{j X} \\
(\boldsymbol{\mu} \mathbf{\Omega} / \mathbf{m})\end{array}$ & $\begin{array}{c}\text { Distance between } \\
\text { loads (m) }\end{array}$ \\
\hline 4/0 AA phase & $302+\mathrm{j} 431$ & \multirow{2}{*}{27.9} \\
\hline $4 / 0$ ACSR neutral & $350+\mathrm{j} 461$ & \\
\hline
\end{tabular}

\section{REFERENCES}

[1] N. G. Hingorani and L. Gyugyi, Understanding FACTS : concepts and technology of flexible AC transmission systems. New York: IEEE Press, 2000.

[2] S. Y. Hui, C. K. Lee, and F. F. Wu, "Electric Springs: A New Smart Grid Technology," Smart Grid, IEEE Transactions on, vol. 3, pp. 1552-1561, 2012.

[3] A. Brooks, E. Lu, D. Reicher, C. Spirakis, and B. Weihl, "Demand Dispatch," IEEE Power and Energy Magazine,, vol. 8, pp. 20-29, 2010.

[4] D. Westermann and A. John, "Demand Matching Wind Power Generation With Wide-Area Measurement and
Demand-Side Management," IEEE Transactions on Energy Conversion, vol. 22, pp. 145-149, 2007.

[5] C. K. Lee and S. Y. Hui, "Reduction of Energy Storage Requirements in Future Smart Grid Using Electric Springs," Smart Grid, IEEE Transactions on, vol. PP, pp. 1-7, 2013.

[6] C. K. Lee, B. Chaudhuri, and S. Y. Hui, "Hardware and Control Implementation of Electric Springs for Stabilizing Future Smart Grid With Intermittent Renewable Energy Sources," Emerging and Selected Topics in Power Electronics, IEEE Journal of, vol. 1, pp. 18-27, 2013.

[7] C. K. Lee, N. R. Chaudhuri, B. Chaudhuri, and S. Y. R. Hui, "Droop Control of Distributed Electric Springs for Stabilizing Future Power Grid," Smart Grid, IEEE Transactions on, vol. 4, pp. 1558-1566, 2013.

[8] J. Dixon, L. Moran, J. Rodriguez, and R. Domke, "Reactive Power Compensation Technologies: State-ofthe-Art Review," Proceedings of the IEEE, vol. 93, pp. 2144-2164, 2005.

[9] T. J. E. Miller, Reactive power control in electric systems. New York; Chichester: Wiley, 1982.

[10] P. Palensky and D. Dietrich, "Demand Side Management: Demand Response, Intelligent Energy Systems, and Smart Loads," IEEE Transactions on Industrial Informatics, vol. 7, pp. 381-388, 2011.

[11] M. Parvania and M. Fotuhi-Firuzabad, "Demand Response Scheduling by Stochastic SCUC," IEEE Transactions on Smart Grid, vol. 1, pp. 89-98, 2010.

[12] M. Pedrasa, T. D. Spooner, and I. F. MacGill, "Scheduling of Demand Side Resources Using Binary Particle Swarm Optimization," IEEE Transactions on Power Systems, vol. 24, pp. 1173-1181, 2009.

[13] N. R. Chaudhuri, C. K. Lee, B. Chaudhuri, and S. Y. R. Hui, "Dynamic Modeling of Electric Springs," IEEE Transactions on Smart Grids, in press, 2014.

[14] "Hong Kong Energy End-use Data 2013," Electrical \& Mechanical Services Department, Hong Kong Special Administration Region, 2013, 2013.

[15] S. C. Tan, C. K. Lee, and C. K. R. Hui, "General SteadyState Analysis and Control Principle of Electric Springs With Active and Reactive Power Compensations," Power Electronics, IEEE Transactions on, vol. 28, pp. 3958-3969, 2013.

[16] (2006). IEEE 13-node Test Feeder. Available: http://ewh.ieee.org/soc/pes/dsacom/testfeeders/ 